Check for updates

Cite this: RSC Adv., 2021, 11, 25995

Received 30th March 2021

Accepted 28th June 2021

DOI: $10.1039 / \mathrm{d} 1 \mathrm{ra02515e}$

rsc.li/rsc-advances

\title{
Novel nano-architectured carbon quantum dots (CQDs) with phosphorous acid tags as an efficient catalyst for the synthesis of multisubstituted $4 \mathrm{H}$ - pyran with indole moieties under mild conditions $\uparrow$
}

\author{
Milad Mohammadi Rasooll, a Mahmoud Zarei, (D) *a Mohammad Ali Zolfigol, (D) *a \\ Hassan Sepehrmansourie, ${ }^{a}$ Afsaneh Omidi, ${ }^{b}$ Masoumeh Hasani (D)*b \\ and Yanlong Gu (D) ${ }^{c}$
}

\begin{abstract}
In this work, a new nano-structured catalyst with phosphorus acid moieties, synthesized by the reaction of carbon quantum dots (CQDs) and phosphorus acid under refluxing $\mathrm{EtOH}$. The structure and morphology of $\mathrm{CQDs}-\mathrm{N}\left(\mathrm{CH}_{2} \mathrm{PO}_{3} \mathrm{H}_{2}\right)_{2}$ were fully characterized using various techniques such as Fourier transform infrared (FT-IR) spectroscopy, transmission electron microscopy (TEM), scanning electron microscopy (SEM), energy dispersive $X$-ray (EDX) spectroscopy, thermogravimetric (TG) analysis, fluorescence and $X$-ray diffraction (XRD) measurements. The new CQDs- $N\left(C_{2} H_{2} \mathrm{PO}_{3} \mathrm{H}_{2}\right)_{2}$ catalyst was successfully used for the synthesis of 2-amino-6-(2-methyl- $1 \mathrm{H}$-indol-3-yl)-4-phenyl$4 \mathrm{H}$-pyran-3,5-dicarbonitriles by the one-pot reaction of various aromatic aldehydes, 3 - $(1 \mathrm{H}$-indol3-yl)-3-oxopropanenitrile derivatives and malononitrile in refluxing $\mathrm{EtOH}$ and/or ultrasonic irradiation conditions.
\end{abstract}

\section{Introduction}

Carbon quantum dots (CQDs) have recently attracted comprehensive research interest due to their various physicochemical properties and favorable features such as biocompatibility, distinctive optical properties and low cost. $^{1-6}$ In 2004, Xu et al. developed carbon quantum dots (CQDs) during the purification of single-walled carbon nanotubes via a preparative electrophoresis methodology. ${ }^{7}$ Carbon quantum dots (CQDs) have been used in many interesting fields of research such as bioimaging, biosensing, catalysis, heavy metal element sensing and biomolecule/drug delivery. ${ }^{8-13}$ Also, these nanomaterials show intense photoluminescence (PL), arising from quantum-confinement effects. ${ }^{14}$ Materials with phosphorous acid tags have been introduced as catalysts, adsorbents, inhibitors and extractants. ${ }^{15}$ Recently a wide variety of

${ }^{a}$ Department of Organic Chemistry, Faculty of Chemistry, Bu-Ali Sina University,
Hamedan 6517838683, Iran. E-mail: mahmoud8103@yahoo.com; zolf@@basu.ac.ir;
mzolfigol@yahoo.com; Fax: +988 138380709; Tel: +988 138282807
${ }^{b}$ Department of Analytical Chemistry, Faculty of Chemistry, Bu-Ali Sina University,
Hamedan, Iran. E-mail: hasani@basu.ac.ir
${ }^{{ }^{5} S c h o o l ~ o f ~ C h e m i s t r y ~ a n d ~ C h e m i c a l ~ E n g i n e e r i n g, ~ H u a z h o n g ~ U n i v e r s i t y ~ o f ~ S c i e n c e ~ a n d ~}$
Technology, 1037 Luoyu Road, Hongshan District, Wuhan, 430074, China. E-mail:
klgyl@hust.edu.cn $\dagger$ Electronic supplementary information (ESI) available. See DOI: 10.1039/d1ra02515e solid acid catalysts with phosphorous acid functional groups, such as glycoluril, ${ }^{16}$ SBA- $15,{ }^{17}$ a melamine-based nano catalyst, ${ }^{18}$ metal-organic frameworks (MOFs) ${ }^{19-21}$ and uric acid, ${ }^{22}$ have been reported for the synthesis of organic compounds.

Organic compounds with indole scaffolds have diverse biological and pharmacological applications such as antifungal, optimal inhibitory, anticholinergic, antihypertensive, antibacterial, antiviral, cardiovascular, anticonvulsant and antiproliferative activities. ${ }^{23-30}$ Also, several natural products and pharmaceutically important compounds which act as antitumor, anticancer, anti-inflammatory, hypoglycemic, antipyretic or analgesic reagents have indole scaffolds in their structures. ${ }^{31}$ Additionally, $4 \mathrm{H}$-pyran derivative structures are an important category of heterocyclic compounds due to their biological properties, such as their anticoagulant, anticancer, antioxidant, spasmolytic, diuretic and anti-anaphylactic activities (Fig. 1). ${ }^{32-36}$ 2-Amino-4H-pyran derivatives have also been applied as photoactive materials, cosmetics and pigments. ${ }^{37}$ Ultrasonic irradiation has been widely applied for the preparation of organic compounds with biological activity. On the other hand, ultrasonic irradiation as an efficient strategy for the preparation of materials in chemical synthesis has received great attention in chemical processes. ${ }^{38,39}$ One of the major advantages of ultrasonic irradiation is the controllability of the time and energy power. 

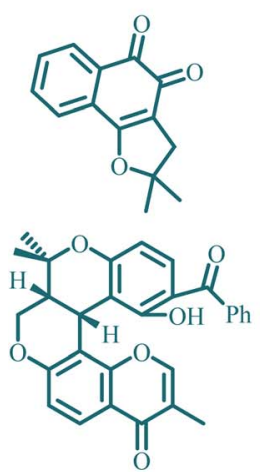<smiles>O=c1cc(N2CCOCC2)oc2c(-c3ccccc3)cccc12</smiles>

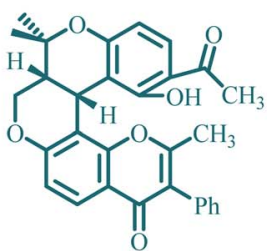<smiles>CC(=O)N[C@H]1[C@H](NC(=N)N)C=C(C(=O)O)O[C@]1(O)[C@H](O)CO</smiles><smiles>O=c1cc(N2CCOCC2)oc2c(-c3ccccc3)csc12</smiles>

Fig. 1 Structure of pyran compounds with biological properties.

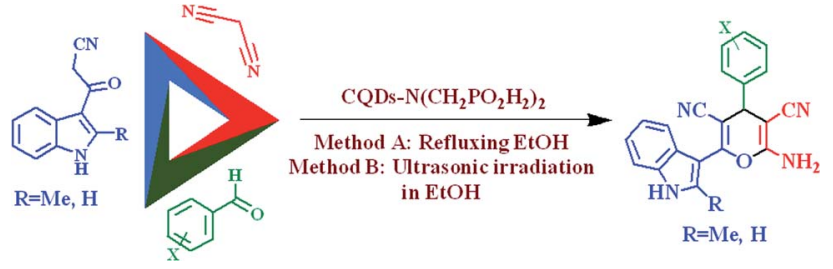

Scheme 1 Synthesis of 4H-pyran-3,5-dicarbonitrile with indole moieties using CQDs- $\mathrm{N}\left(\mathrm{CH}_{2} \mathrm{PO}_{3} \mathrm{H}_{2}\right)_{2}$.

On the basis of the above-mentioned facts, the synthesis of $4 H$-pyran-3,5-dicarbonitrile and pyridines with indole moieties in the presence of reusable solid acid catalysts is our main research interest. With this aim, CQDs- $\left(\mathrm{CH}_{2} \mathrm{PO}_{3} \mathrm{H}_{2}\right)_{2}$, as a novel carbon quantum dot (CQD) nano-catalyst structure with phosphorus acid tags, was synthesized, characterized and used in the synthesis of 4H-pyran-3,5-dicarbonitrile with indole moieties, both in refluxing EtOH and ultrasonic irradiation in EtOH as a solvent (Scheme 1).

\section{Experimental}

\subsection{General procedure for the preparation of CQDs-} $\mathrm{N}\left(\mathrm{CH}_{2} \mathrm{PO}_{3} \mathrm{H}_{2}\right)_{2}$

Initially, carbon quantum dots (CQDs) were synthesized by adding citric acid (1.05 g, $5.5 \mathrm{mmol}$ ), ethane-1,2-diamine ( $5 \mathrm{mmol}, 0.33 \mathrm{~mL}$ ) and $10 \mathrm{~mL} \mathrm{H}_{2} \mathrm{O}$ under ultrasonic irritation for 30 min. ${ }^{40}$ Then, this mixture was kept in a Teflon- lined stainless-steel autoclave at $200{ }^{\circ} \mathrm{C}$ for $6 \mathrm{~h}$. After the reaction was completed, a dark precipitate appeared, which was filtered by centrifugation (1000 rpm, $20 \mathrm{~min})$. The carbon quantum dots (CQDs) were dried under vacuum. Then, in a $25 \mathrm{~mL}$ round-bottomed flask connected to a reflux condenser, carbon quantum dots (CQDs) (0.5 g), paraformaldehyde ( $4 \mathrm{mmol}, 0.12 \mathrm{~g}$ ), phosphorous acid ( $2 \mathrm{mmol}$, $0.164 \mathrm{~g}), p$-TSA $(0.01 \mathrm{~g})$ and ethanol $(10 \mathrm{~mL})$ were added and refluxed for 8 hours. A white solid appeared, which was filtered by centrifugation $(1000 \mathrm{rpm}, 10 \mathrm{~min})$. The obtained CQDs-N $\left(\mathrm{CH}_{2} \mathrm{PO}_{3} \mathrm{H}_{2}\right)_{2}$ was dried under vacuum (Scheme 2).

\subsection{General procedure for the synthesis of 2-amino-6-(2- methyl-1H-indol-3-yl)-4-phenyl-4H-pyran-3,5-dicarbonitrile using CQDs- $\mathrm{N}\left(\mathrm{CH}_{2} \mathrm{PO}_{3} \mathrm{H}_{2}\right)_{2}$ as a catalyst}

In a $20 \mathrm{~mL}$ round-bottomed flask, a mixture of aldehyde (1 mmol), 3-(1H-indol-3-yl)-3-oxopropanenitrile derivatives (1 $\mathrm{mmol})$, malononitrile (1.1 mmol, $0.073 \mathrm{~g})$, CQDs$\mathrm{N}\left(\mathrm{CH}_{2} \mathrm{PO}_{3} \mathrm{H}_{2}\right)_{2}(10 \mathrm{mg})$ as a catalyst and EtOH $(10 \mathrm{~mL})$ was stirred under reflux conditions (method $\mathrm{A}$ ) or under ultrasonic irradiation (method B). After the completion of the reaction (monitored by TLC $n$-hexane/ethyl acetate; $7: 3)$, PEG (10 mL) was added to the mixture and the catalyst was separated by centrifugation (1000 rpm, $10 \mathrm{~min}$ ). Finally, the mixture was poured into $\mathrm{H}_{2} \mathrm{O}$ and the precipitate was filtered off. The obtained residue was washed with warm ethanol and dried at $100{ }^{\circ} \mathrm{C}$ (Scheme 1).

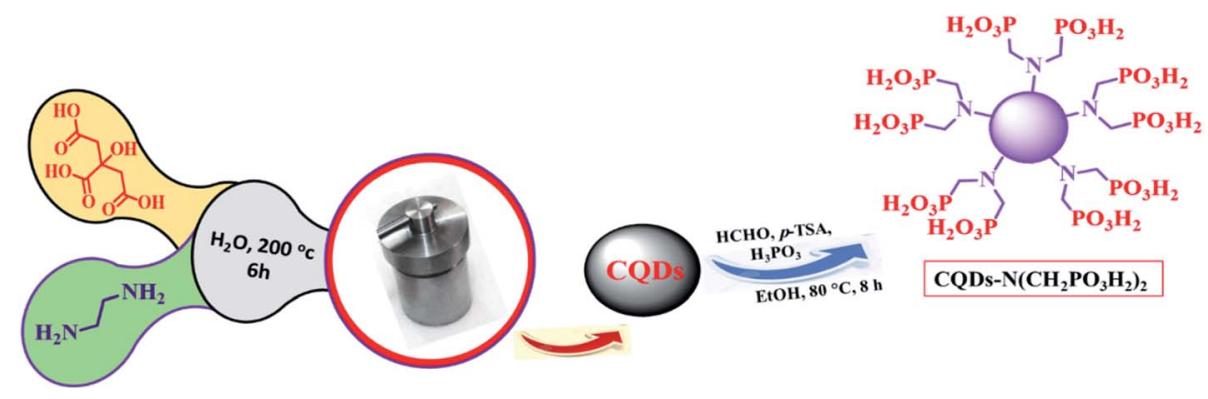

Scheme 2 Preparation of CQDs $-\mathrm{N}\left(\mathrm{CH}_{2} \mathrm{PO}_{3} \mathrm{H}_{2}\right)_{2}$ as the desired catalyst. 


\section{Result and discussion}

\subsection{Synthesis and characterization of the catalyst with} phosphorous acid tags

Since molecules with indole moieties have been considered as candidates with biological interest ${ }^{\mathbf{4 1}}$ and we have conducted a literature survey for publishing a comprehensive review on the subject of bis and tris indolyl methanes, ${ }^{\mathbf{4 2}}$ we decided to report a catalytic methodology for the synthesis of multisubstituted $4 H$-pyran with indole moieties (Schemes 1 and 2). Here, 2-amino-6-(2-methyl- $1 H$-indol-3-yl)-4-phenyl$4 H$-pyran-3,5-dicarbonitriles were successfully synthesized in the presence of CQDs- $\mathrm{N}\left(\mathrm{CH}_{2} \mathrm{PO}_{3} \mathrm{H}_{2}\right)_{2}$, various aromatic aldehydes, 3-(1H-indol-3-yl)-3-oxopropanenitrile derivatives and malononitrile both in refluxing EtOH and/or ultrasonic irradiation conditions.

At first, the desired catalyst CQDs- $\mathrm{N}\left(\mathrm{CH}_{2} \mathrm{PO}_{3} \mathrm{H}_{2}\right)_{2}$ was prepared according to Scheme 2. This novel nano-structure catalyst was fully characterized by applying FT-IR spectroscopy, XRD spectroscopy, FE-SEM, energy dispersive X-ray spectroscopy (EDS), transmission electron microscopy (TEM), TG and fluorescence analysis.

The FT-IR spectra of carbon quantum dots (CQDs) and CQDs- $\mathrm{N}\left(\mathrm{CH}_{2} \mathrm{PO}_{3} \mathrm{H}_{2}\right)_{2}$ are compared in Fig. 2. The broad peak at $2600-3500 \mathrm{~cm}^{-1}$ is related to the $\mathrm{OH}$ of the $\mathrm{PO}_{3} \mathrm{H}_{2}$ functional groups. The absorption bands at 1015 and $1050 \mathrm{~cm}^{-1}$ are related to $\mathrm{P}-\mathrm{O}$ bond stretching and the band at $1128 \mathrm{~cm}^{-1}$ is related to $\mathrm{P}=\mathrm{O}$. The differences between the FT-IR spectra of the carbon quantum dots (CQDs) and CQDs$\mathrm{N}\left(\mathrm{CH}_{2} \mathrm{PO}_{3} \mathrm{H}_{2}\right)_{2}$ verified the structure of the catalyst.

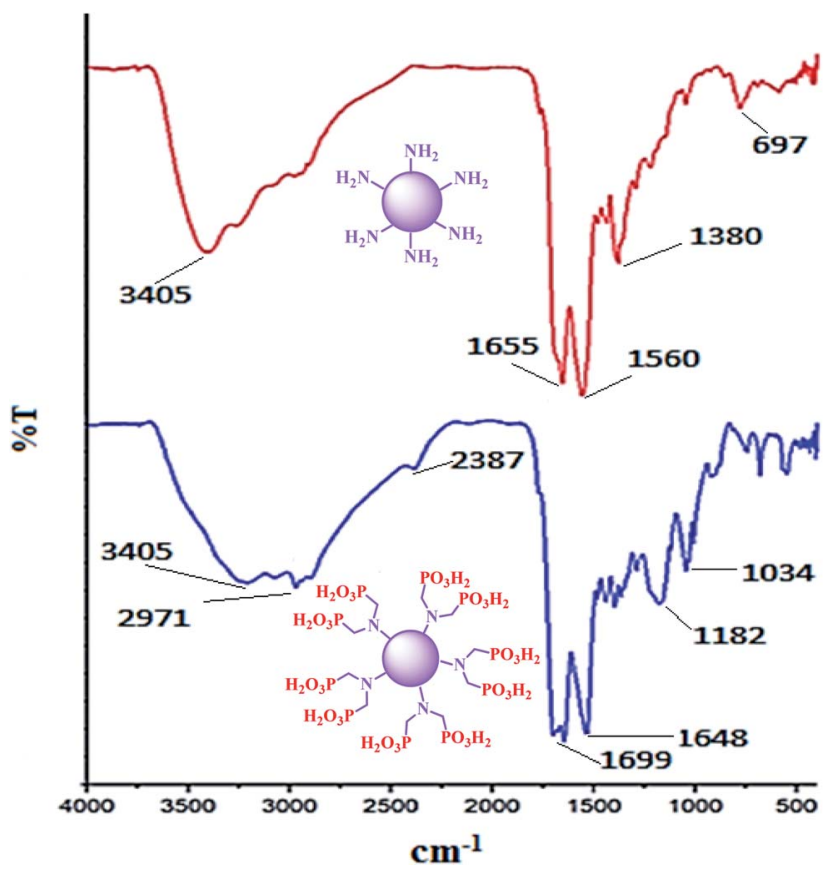

Fig. 2 Comparison of the FT-IR spectra of the CQDs and CQDs$\mathrm{N}\left(\mathrm{CH}_{2} \mathrm{PO}_{3} \mathrm{H}_{2}\right)_{2}$.

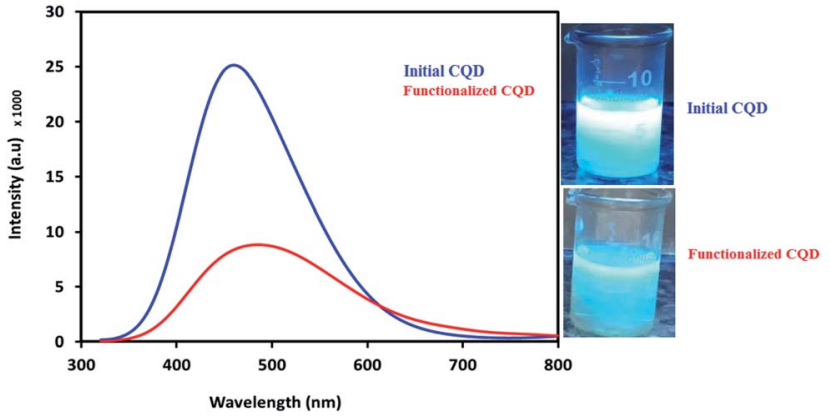

Fig. 3 Fluorescence spectra of the initial CQDs and functionalized CQDs.

Following this, the fluorescence features of the initial CQDs and functionalized CQDs were investigated for the evaluation of the synthesized CQDs and the effect of postfunctionalization on the surface of the final catalyst. As can be seen in Fig. 3, the initial synthesized CQDs display a high-intensity emission peak at $450 \mathrm{~nm}$ (peak a). But the fluorescence intensity of the functionalized CQDs with $\mathrm{PO}_{3} \mathrm{H}_{2}$ groups is decreased and shifted towards longer wavelengths (the red shift effect). Many factors are effective for amplifying or attenuating the fluorescence intensity by affecting the resonance system, including structural rigidity, steric effect interactions, temperature, solvent, $\mathrm{pH}$, the presence of para-magnetite species, heavy atoms and electron donor/acceptor groups. It can be proposed that the presence of larger $\mathrm{PO}_{3} \mathrm{H}_{2}$ groups instead of the smaller proton groups (Scheme 1) can have a negative effect on the fluorescence intensity due to the steric effects. In the other words, the presence of the large $\mathrm{PO}_{3} \mathrm{H}_{2}$ groups, along with the possible rotation of these groups, reduces the symmetry of the molecule. So, increasing the mobility of the molecule will reduce the fluorescence intensity of the functionalized CQDs due to the decreased rigidity and disturbance of the conjugated system. The decreasing fluorescence intensity of

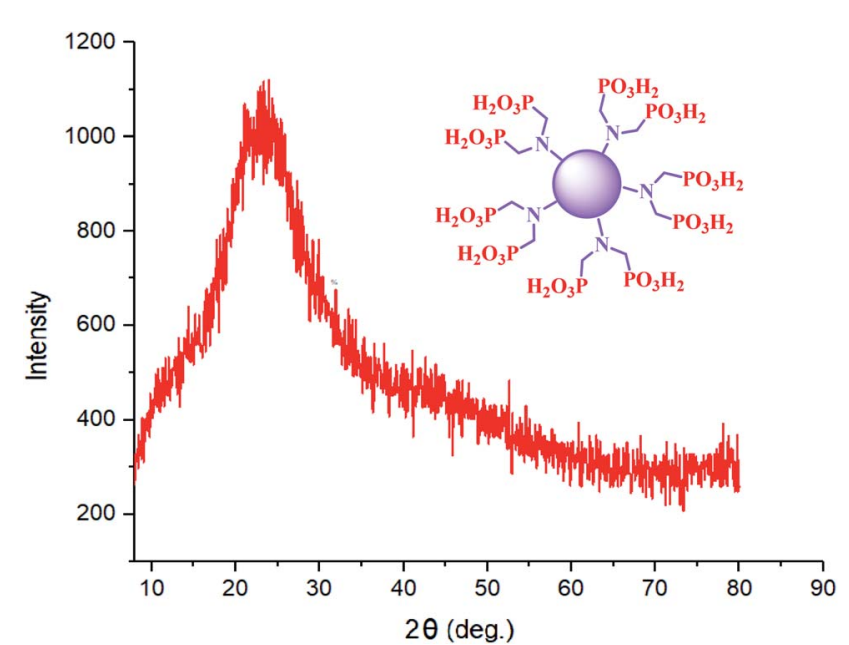

Fig. 4 X-ray diffraction (XRD) pattern of CQDs functionalized with $\mathrm{PO}_{3} \mathrm{H}_{2}$ groups. 
the functionalized CQDs compared to that of the initial CQDs can be a reason for the stabilization of $\mathrm{PO}_{3} \mathrm{H}_{2}$ functional groups on the initial CQD surface. Fig. 3 shows photographic images of the decreased fluorescence intensity of the initial CQDs after post-modification with the $\mathrm{PO}_{3} \mathrm{H}_{2}$ groups.

The XRD pattern for CQDs- $\mathrm{N}\left(\mathrm{CH}_{2} \mathrm{PO}_{3} \mathrm{H}_{2}\right)_{2}$ is shown in the region of $2 \theta=5-80^{\circ}$ (Fig. 4). The broad peak of CQDs$\mathrm{N}\left(\mathrm{CH}_{2} \mathrm{PO}_{3} \mathrm{H}_{2}\right)_{2}$ corresponds to the diffraction lines in previously reported literature. ${ }^{43}$ Therefore, the structure and morphology of the carbon quantum dots (CQDs) is stable after functionalization with phosphorous acid groups.

The elements that CQDs- $\mathrm{N}\left(\mathrm{CH}_{2} \mathrm{PO}_{3} \mathrm{H}_{2}\right)_{2}$ was composed of were also studied with energy dispersive X-ray (EDX) analysis (Fig. 5). The structure of the catalyst was verified by the existence of $\mathrm{N}, \mathrm{C}, \mathrm{O}$ and $\mathrm{P}$ atoms.

The morphology and particle size of CQDs- $\mathrm{N}\left(\mathrm{CH}_{2} \mathrm{PO}_{3} \mathrm{H}_{2}\right)_{2}$ were also studied from the scanning electron microscopy (SEM) (Fig. 6a and b) and transmission electron microscopy (TEM) images (Fig. 7). The scanning electron microscopy (SEM) of CQDs- $\mathrm{NH}_{2}$ (Fig. 6a) and CQDs-N( $\left(\mathrm{CH}_{2} \mathrm{PO}_{3} \mathrm{H}_{2}\right)_{2}$ (Fig. 6b) did not show different morphologies of these materials. As shown in the transmission electron microscopy images (Fig. 7), nanoparticles of CQDs- $\mathrm{N}\left(\mathrm{CH}_{2} \mathrm{PO}_{3} \mathrm{H}_{2}\right)_{2}$ are approximately 5-15 nm with a narrow size, which are regularly arranged and not completely stacked.

The thermal gravimetric (TG) analysis results for CQDs$\mathrm{N}\left(\mathrm{CH}_{2} \mathrm{PO}_{3} \mathrm{H}_{2}\right)_{2}$ are shown in Fig. 8. Two declining stages were observed for CQDs- $\left(\mathrm{CH}_{2} \mathrm{PO}_{3} \mathrm{H}_{2}\right)_{2}$ in Fig. 8. The first weight loss (which includes about 5\% weight loss) was related to the evaporation of the solvents (organic and water). The second weight loss is at $400{ }^{\circ} \mathrm{C}$ (includes about $40 \%$ weight loss), which is linked to the breaking of the bonds of $\mathrm{N}-\mathrm{C}-\mathrm{PO}_{3} \mathrm{H}_{2}$ of the structure of CQDs- $\mathrm{N}\left(\mathrm{CH}_{2} \mathrm{PO}_{3} \mathrm{H}_{2}\right)_{2}$.

\subsection{Catalytic properties of the catalyst with phosphorous acid tags}

After the synthesis and characterization of CQDs$\mathrm{N}\left(\mathrm{CH}_{2} \mathrm{PO}_{3} \mathrm{H}_{2}\right)_{2}$, it was applied for the synthesis of 2-amino-6(2-methyl- $1 H$-indol-3-yl)-4-phenyl-4H-pyran-3,5-

dicarbonitrile derivatives with indole and pyran moieties. The above-mentioned products were obtained by the

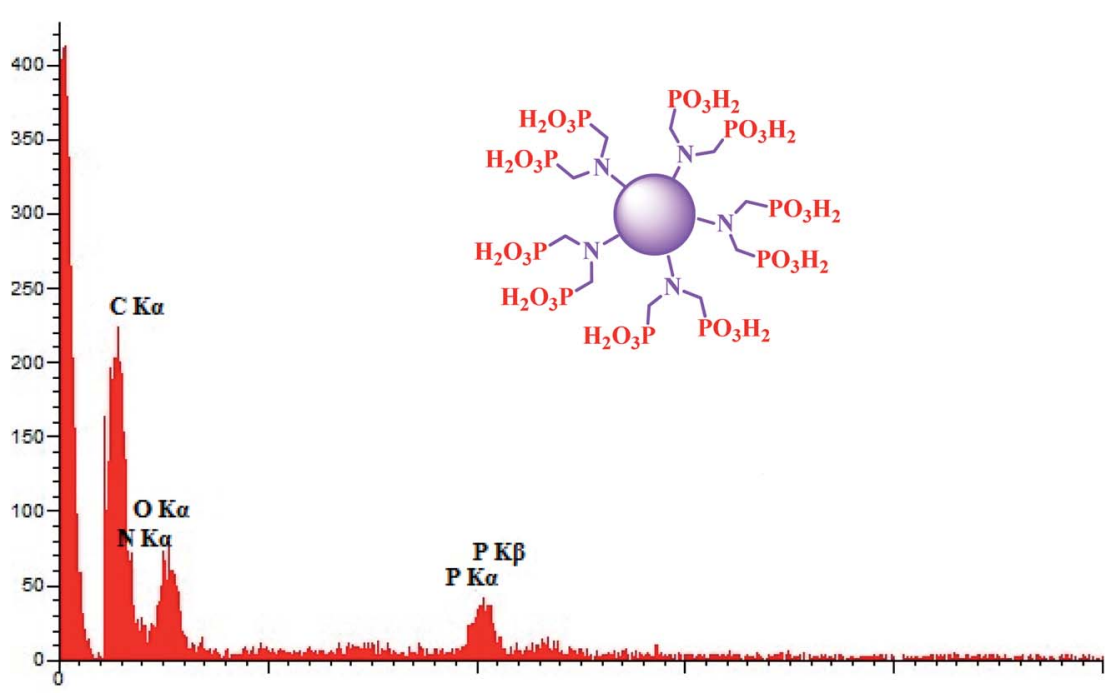

Fig. 5 Energy dispersive $\mathrm{X}$-ray (EDX) analysis of $\mathrm{CQDs}-\mathrm{N}\left(\mathrm{CH}_{2} \mathrm{PO}_{3} \mathrm{H}_{2}\right)_{2}$.
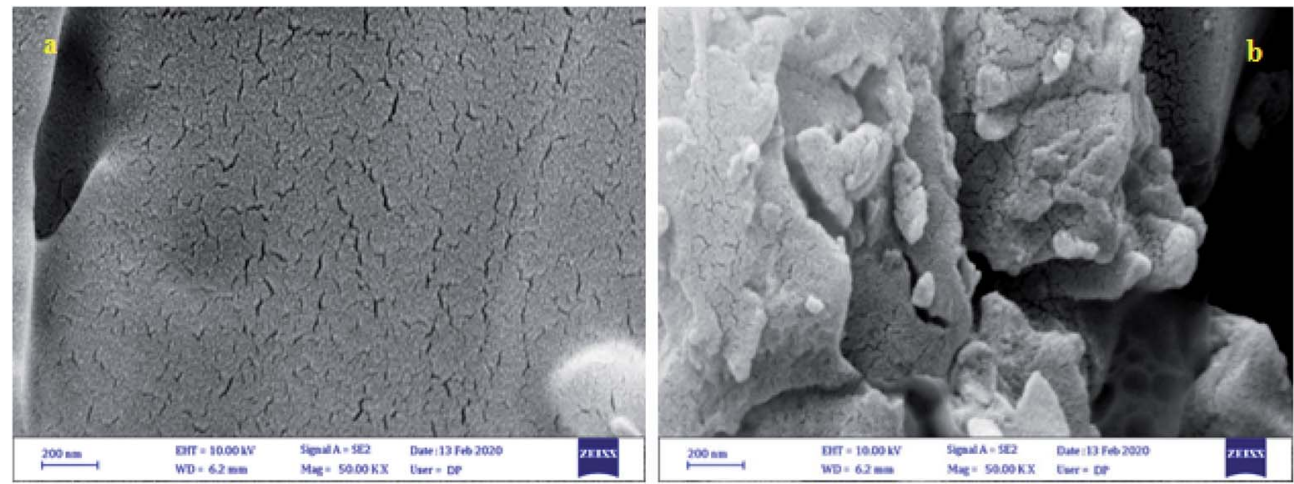

Fig. 6 Scanning electron microscopy (SEM) images of $\mathrm{CQDs}-\mathrm{NH}_{2}(\mathrm{a})$ and $\mathrm{CQDs}-\mathrm{N}\left(\mathrm{CH}_{2} \mathrm{PO}_{3} \mathrm{H}_{2}\right)_{2}$ (b). 


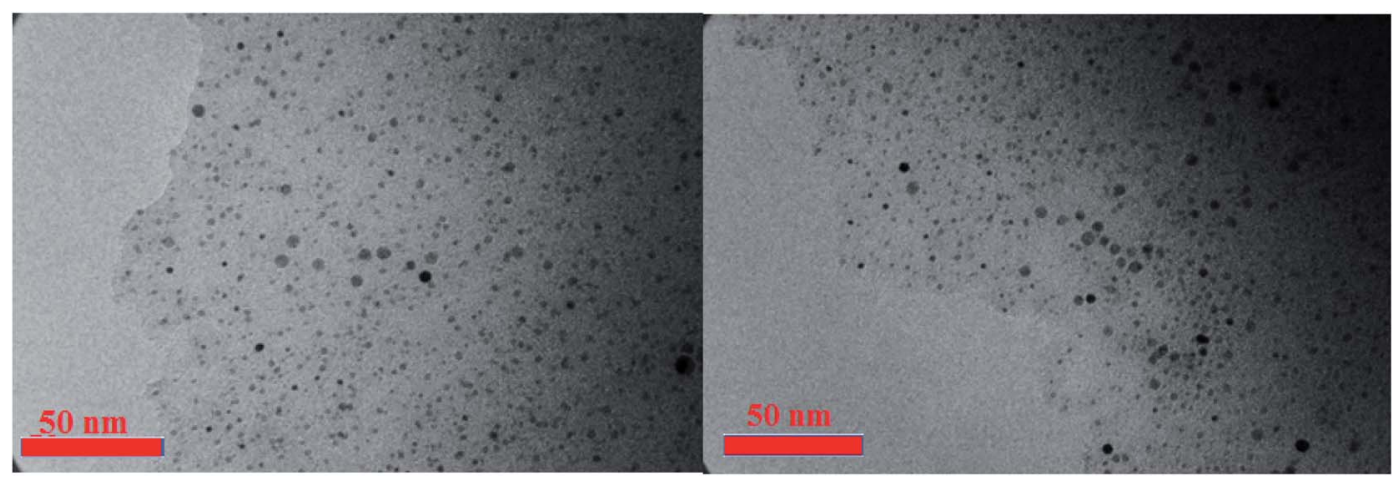

Fig. 7 Transmission electron microcopy (TEM) images of CQDs- $\mathrm{N}\left(\mathrm{CH}_{2} \mathrm{PO}_{3} \mathrm{H}_{2}\right)_{2}$.

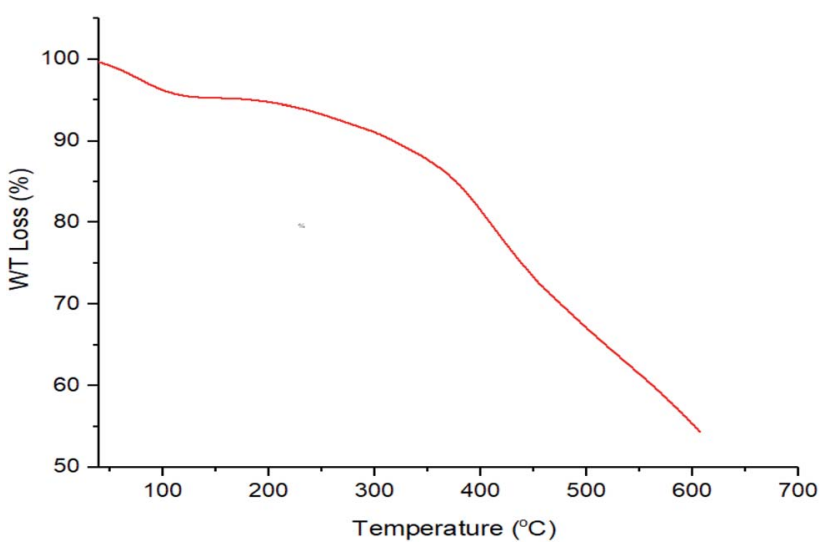

Fig. 8 Thermal gravimetric (TG) analysis of CQDs $-\mathrm{N}\left(\mathrm{CH}_{2} \mathrm{PO}_{3} \mathrm{H}_{2}\right)_{2}$.

reaction of 4-chloro-benzaldehyde (1 mmol, $0.14 \mathrm{~g}), 3-\left(1 \mathrm{H}^{-}\right.$ indol-3-yl)-3-oxopropanenitrile (1 mmol, $0.184 \mathrm{~g}$ ) and malononitrile ( $1.1 \mathrm{mmol}, 0.073 \mathrm{~g})$ as a model for the optimization

Table 1 Effects of different amounts of catalyst, temperature and solvent $(5 \mathrm{~mL})$ on the synthesis of 2-amino-4-(4-chlorophenyl)-6(1H-indol-3-yl)- $4 H$-pyran-3,5-dicarbonitrile

\begin{tabular}{|c|c|c|c|c|c|}
\hline Entry & Solvent & Catalyst (mg) & Temp. $\left({ }^{\circ} \mathrm{C}\right)$ & Time (min) & Yield (\%) \\
\hline 1 & EtOH & 10 & Reflux & 25 & 89 \\
\hline 2 & EtOH & 10 & 50 & 45 & 55 \\
\hline 3 & EtOH & 10 & 25 & 80 & 30 \\
\hline 4 & EtOH & 5 & Reflux & 35 & 70 \\
\hline 5 & EtOH & 20 & Reflux & 30 & 75 \\
\hline 6 & EtOH & - & Reflux & 120 & 25 \\
\hline 7 & DMF & 10 & 100 & 90 & 60 \\
\hline 8 & $\mathrm{H}_{2} \mathrm{O}$ & 10 & Reflux & 120 & - \\
\hline 9 & $\mathrm{CH}_{3} \mathrm{CN}$ & 10 & Reflux & 120 & Trace \\
\hline 10 & $n$-hexane & 10 & Reflux & 120 & - \\
\hline 11 & $\mathrm{CHCl}_{3}$ & 10 & Reflux & 100 & 50 \\
\hline 12 & Toluene & 10 & Reflux & 120 & - \\
\hline 13 & $\mathrm{MeOH}$ & 10 & Reflux & 50 & 60 \\
\hline 14 & $\mathrm{CH}_{2} \mathrm{Cl}_{2}$ & 10 & Reflux & 50 & 35 \\
\hline 15 & EtOAc & 10 & Reflux & 120 & - \\
\hline 16 & - & 10 & 100 & 30 & 60 \\
\hline 17 & - & 10 & 25 & 120 & 35 \\
\hline 18 & - & 10 & 50 & 50 & 45 \\
\hline
\end{tabular}

of the reaction conditions. The optimization data is listed in Table 1. As shown in Table 1, the best synthesis of 2-amino-4(4-chlorophenyl)-6-(1H-indol-3-yl)-4H-pyran-3,5-dicarbonitrile was achieved in the presence of $10 \mathrm{mg}$ CQDs- $\mathrm{N}\left(\mathrm{CH}_{2} \mathrm{PO}_{3} \mathrm{H}_{2}\right)_{2}$ in EtOH $(5 \mathrm{~mL})$ as the solvent (entry 1 , Table 1 ). The model reaction was also studied using several solvents such as $\mathrm{H}_{2} \mathrm{O}, \mathrm{CH}_{3} \mathrm{CN}$, nhexane, $\mathrm{CHCl}_{3}$, toluene, $\mathrm{MeOH}, \mathrm{DMF}$, $\mathrm{EtOH}, \mathrm{CH}_{2} \mathrm{Cl}_{2}$ and EtOAc ( $5 \mathrm{~mL}$ ), as well as a solvent-free condition, in the presence of $10 \mathrm{mg}$ of CQDs-N( $\left(\mathrm{CH}_{2} \mathrm{PO}_{3} \mathrm{H}_{2}\right)_{2}$. The results of the reaction show that the yield and time were not improved when using other amounts of catalyst (Table 1, entries 16-18).

After optimizing the reaction conditions, CQDs$\mathrm{N}\left(\mathrm{CH}_{2} \mathrm{PO}_{3} \mathrm{H}_{2}\right)_{2}(10 \mathrm{mg})$ was applied to synthesise a good range of desired compounds using various aromatic aldehydes bearing electron-donating groups, electron-withdrawing groups and heterocycles, as well as malononitrile and 3-(1H-indol-3-yl)-3oxopropanenitrile derivatives, both in refluxing EtOH or ultrasonic irradiation conditions (methods A and B, respectively). As shown in Table 2 the obtained results indicated that CQDs$\mathrm{N}\left(\mathrm{CH}_{2} \mathrm{PO}_{3} \mathrm{H}_{2}\right)_{2}$ is appropriate for the preparation of target molecules in high to excellent yields with short reaction times (methods A and B).

In the proposed mechanism, the aldehyde is activated with a proton of the acidic functional groups of CQDs- $\mathrm{N}\left(\mathrm{CH}_{2} \mathrm{PO}_{3} \mathrm{H}_{2}\right)_{2}$ and intermediate (I) is prepared by the reaction of malononitrile with the loss of one molecule of $\mathrm{H}_{2} \mathrm{O}$. In the second step, 3-(1Hindol-3-yl)-3-oxopropanenitrile reacts with intermediate (I) to give intermediate (II) after tautomerization. Then, intermediate (II) gives the desired product after intramolecular cyclization and the loss of another molecule of $\mathrm{H}_{2} \mathrm{O}$ (Scheme 3).

To compare the efficiency of the described CQDs$\mathrm{N}\left(\mathrm{CH}_{2} \mathrm{PO}_{3} \mathrm{H}_{2}\right)_{2}$ for the synthesis of 2-amino-6-(2-methyl-1Hindol-3-yl)-4-phenyl-4 $H$-pyran-3,5-dicarbonitrile that was achieved in the presence of $10 \mathrm{mg}$ of the catalyst by the reaction of 4 -chloro-benzaldehyde ( $1 \mathrm{mmol}, 0.14 \mathrm{~g}), 3-\left(1 \mathrm{H}^{-}\right.$ indol-3-yl)-3-oxopropanenitrile ( $1 \mathrm{mmol}, 0.184 \mathrm{~g}$ ) and malononitrile (1.1 mmol, $0.073 \mathrm{~g}$ ) under the above-mentioned optimized reaction conditions, various organic and inorganic solid acid catalysts for the above reaction were tested (Table 3). As Table 3 indicates, CQDs- $\mathrm{N}\left(\mathrm{CH}_{2} \mathrm{PO}_{3} \mathrm{H}_{2}\right)_{2}$ is the best choice for the synthesis of 2-amino-6-(2-methyl-1H- 


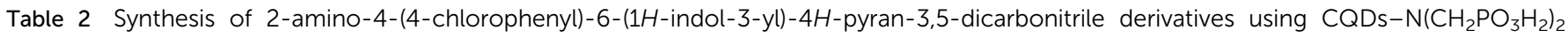
under refluxing $\mathrm{EtOH}$ (method $\mathrm{A}$ ) and ultrasonic irradiation (method $\mathrm{B}$ )

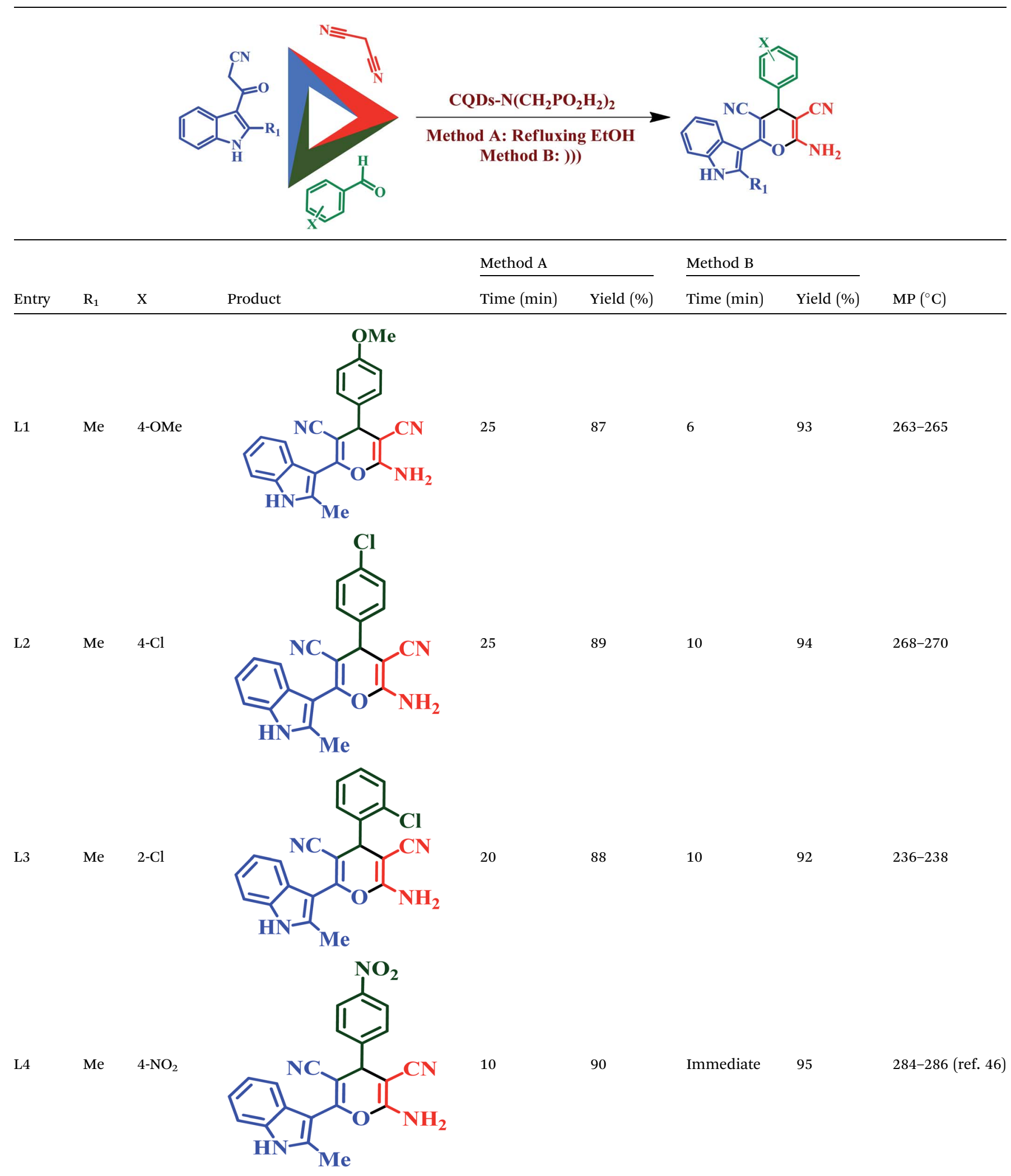


Table 2 (Contd.)

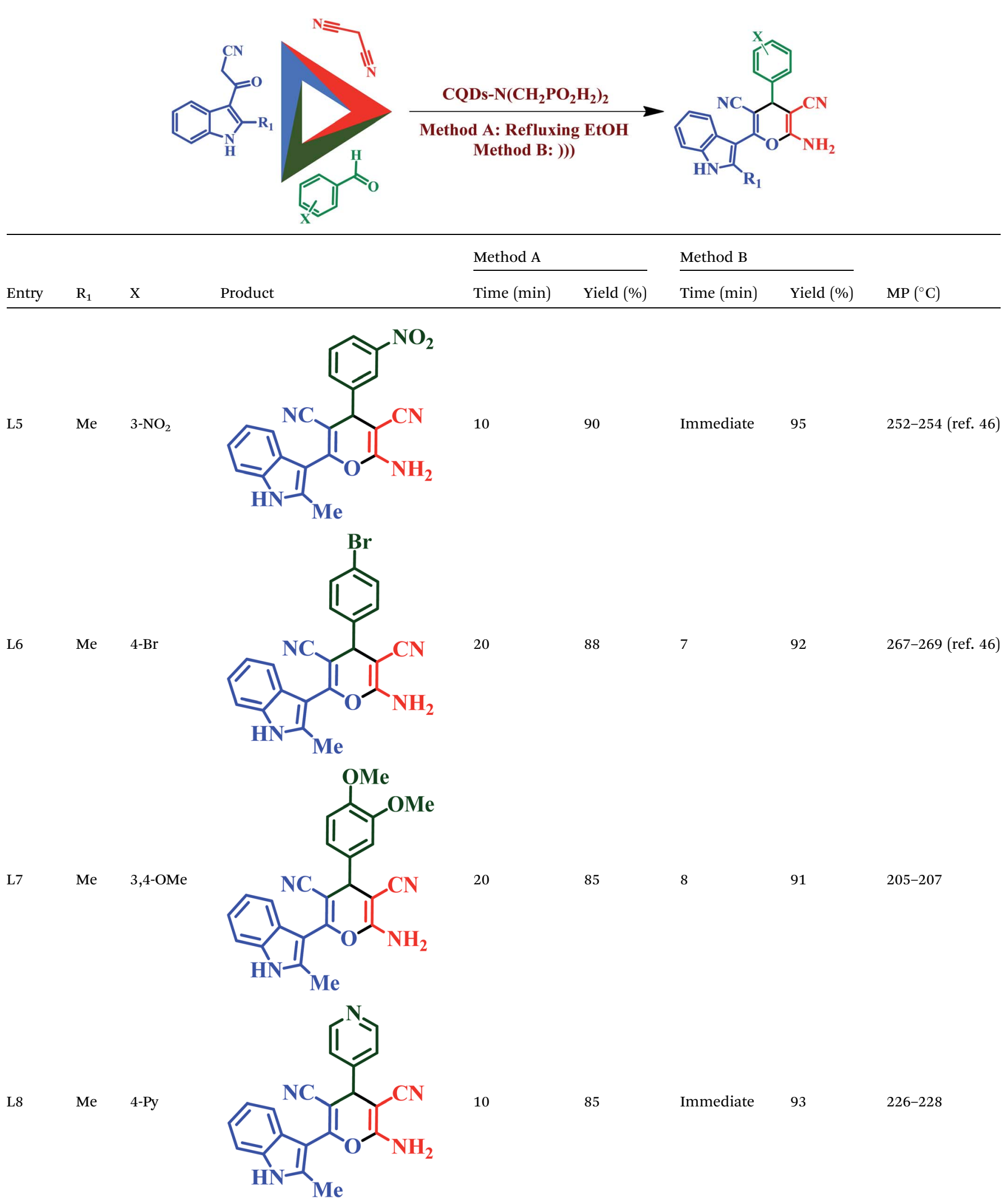


Table 2 (Contd.)

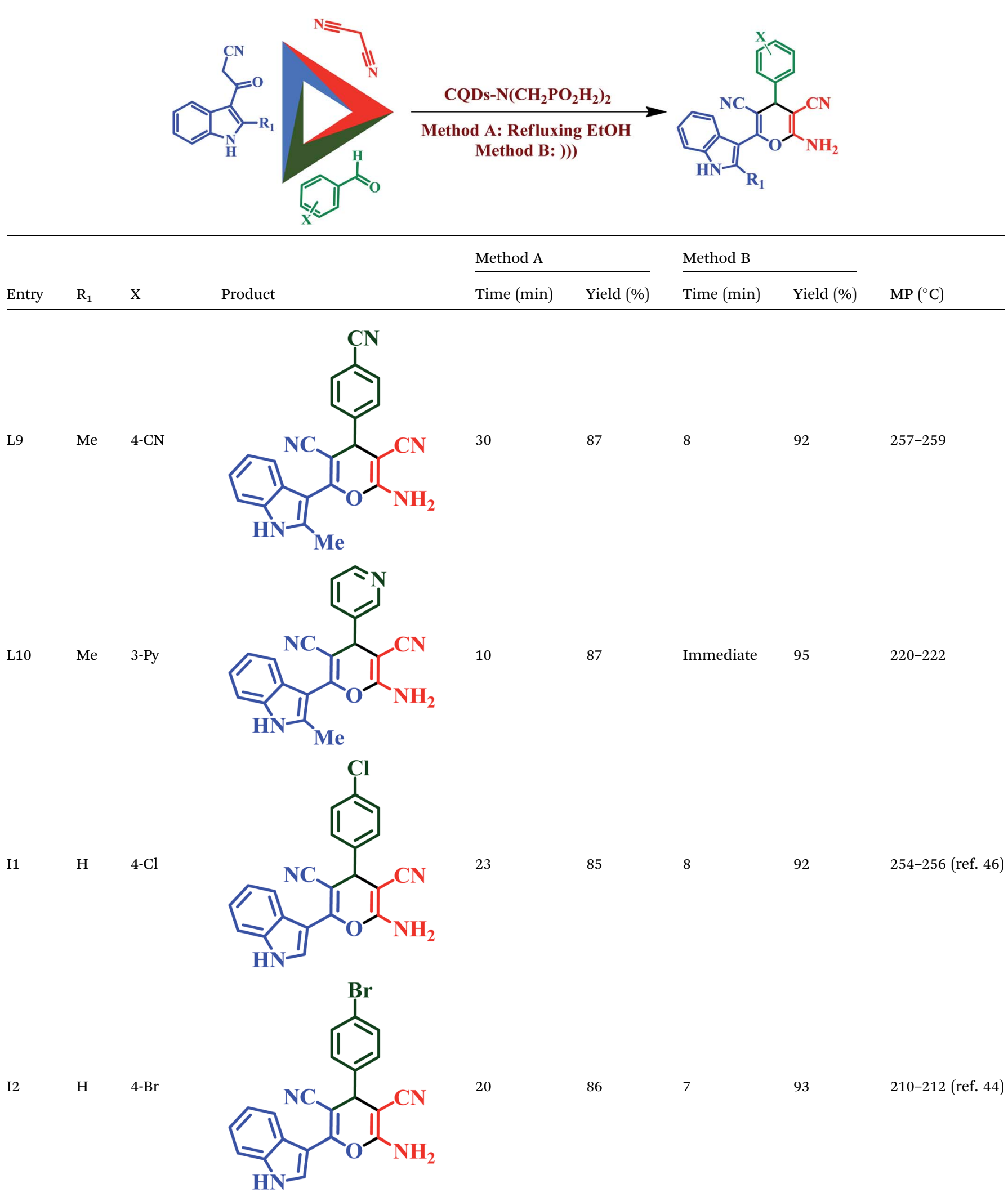


Table 2 (Contd.)

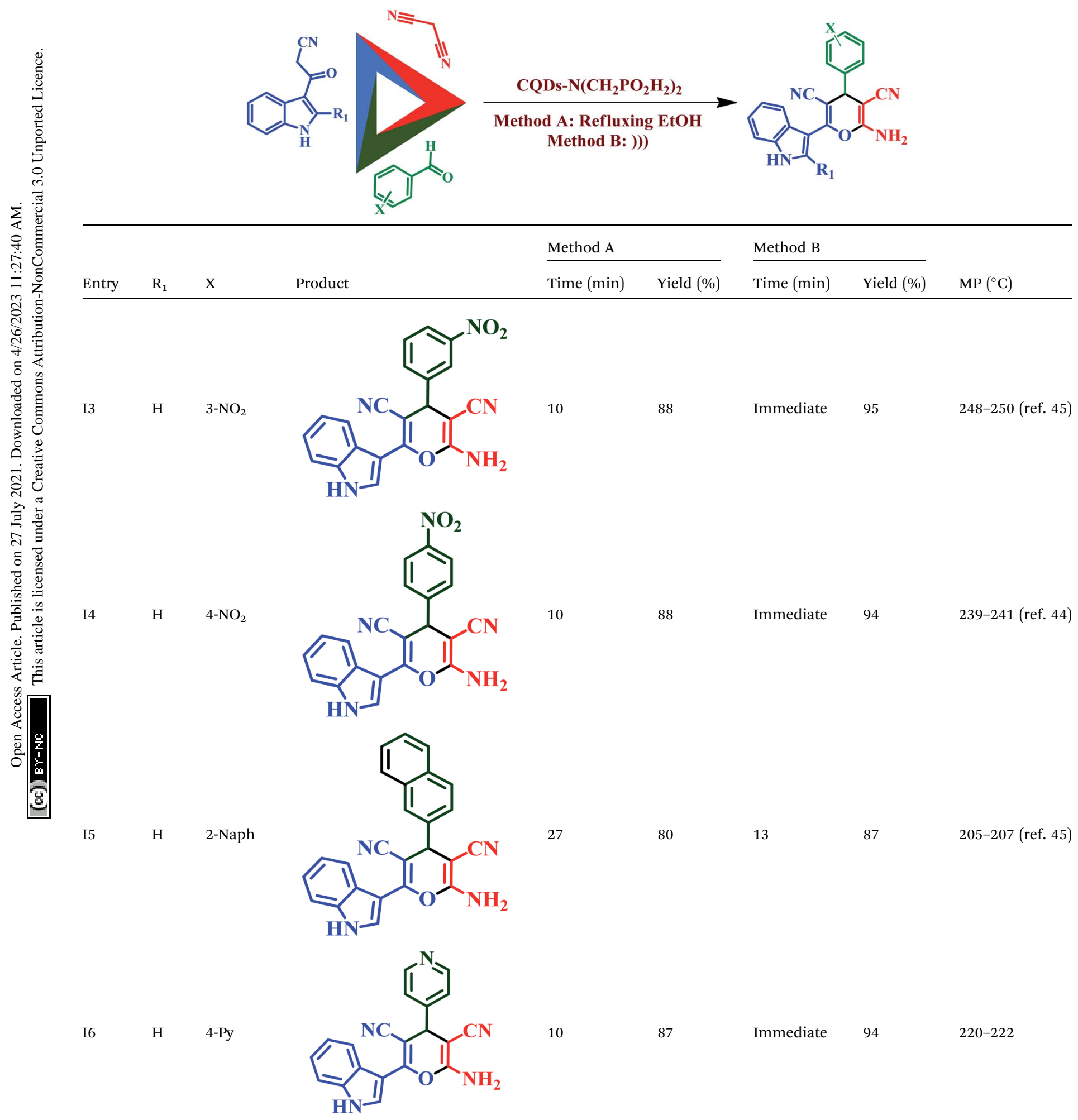


Table 2 (Contd.)

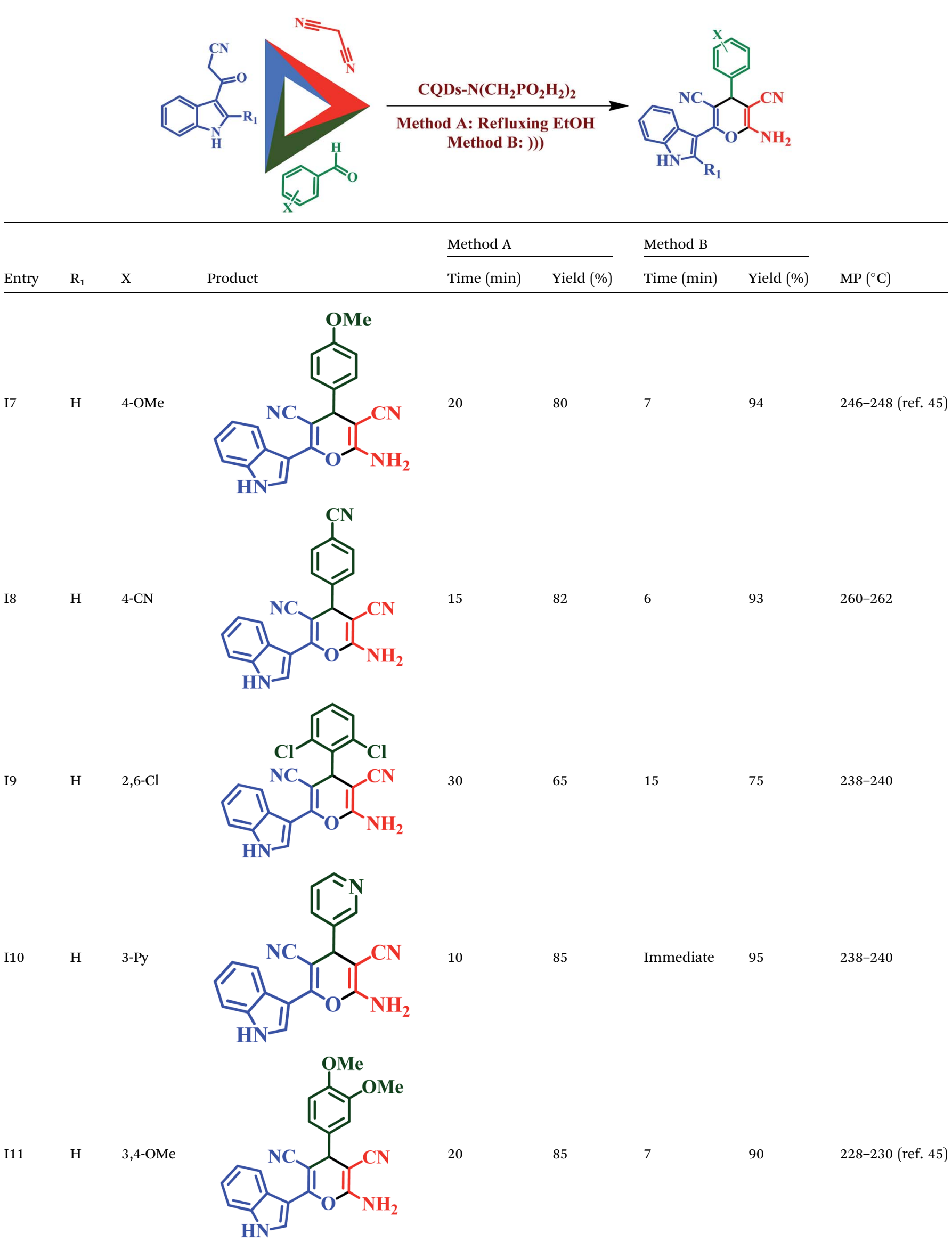




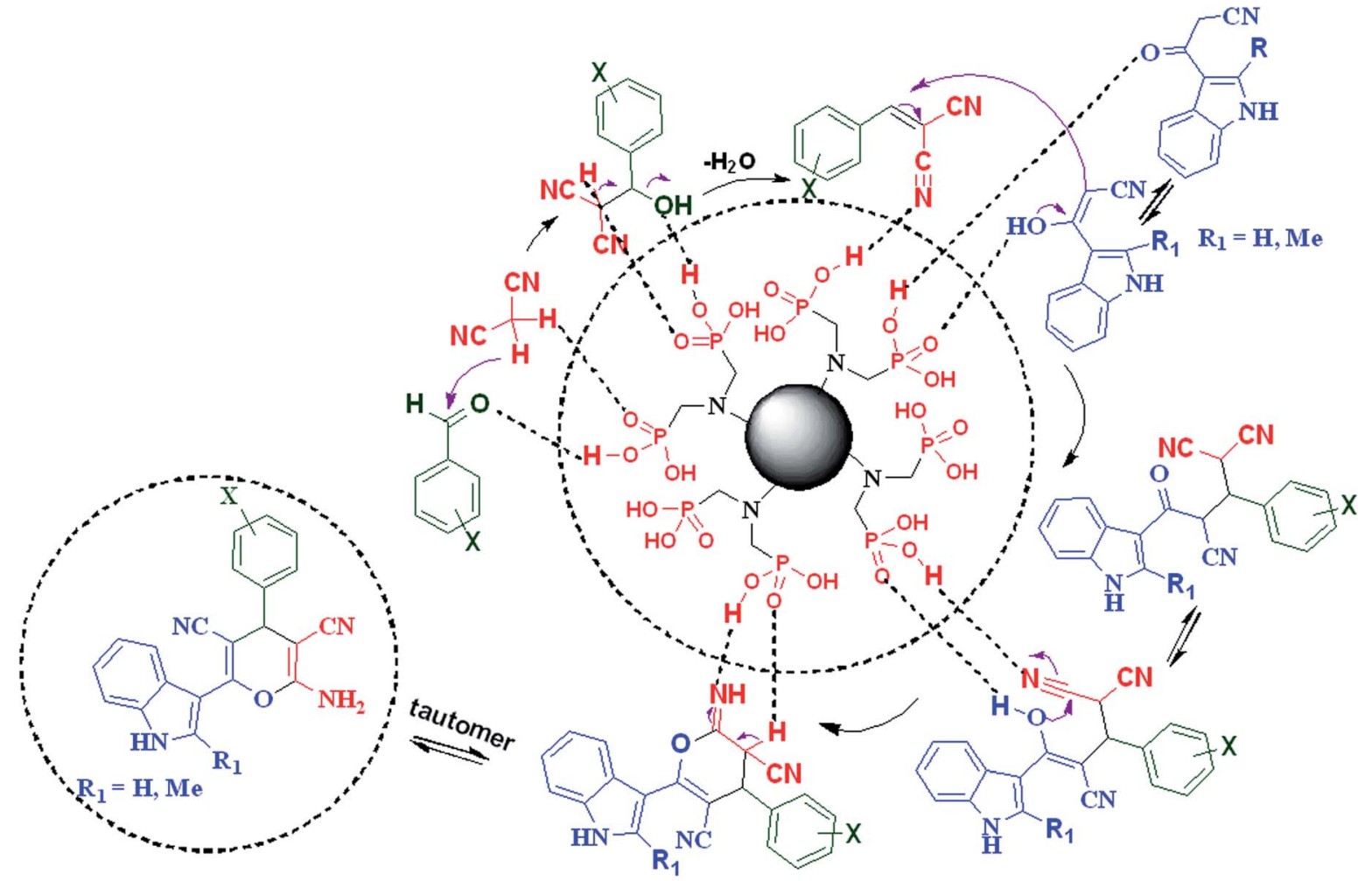

Scheme 3 Proposed mechanism for the synthesis of 2-amino-4-(4-chlorophenyl)-6-(1H-indol-3-yl)-4H-pyran-3,5-dicarbonitrile.

Table 3 Synthesis of 2-amino-4-(4-chlorophenyl)-6-(1H-indol-3yl) $-4 \mathrm{H}$-pyran-3,5-dicarbonitrile the presence of various catalysts using method $A$

\begin{tabular}{|c|c|c|c|c|}
\hline Entry & Catalyst & $(\mathrm{mol} \%)$ & Time (min) & Yield (\%) \\
\hline 1 & $\mathrm{FeCl}_{3}$ & 10 & 80 & 25 \\
\hline 2 & $\mathrm{H}_{2} \mathrm{SO}_{4}$ & 10 & 120 & 20 \\
\hline 3 & $\mathrm{Fe}_{3} \mathrm{O}_{4}$ & $10 \mathrm{mg}$ & 120 & Trace \\
\hline 4 & $\mathrm{NH}_{4} \mathrm{NO}_{3}$ & 10 & 90 & 25 \\
\hline 5 & $\mathrm{CF}_{3} \mathrm{SO}_{3} \mathrm{H}$ & 10 & 70 & 35 \\
\hline 6 & GTBSA $^{47}$ & 10 & 120 & 15 \\
\hline 7 & $\begin{array}{l}\text { MIL-100(Cr)/NHEtN } \\
\left(\mathrm{CH}_{2} \mathrm{PO}_{3} \mathrm{H}_{2}\right)_{2}(\text { ref. } 21)\end{array}$ & 10 & 80 & 60 \\
\hline 8 & $\mathrm{H}_{3}\left[\mathrm{p}\left(\mathrm{W}_{3} \mathrm{O}_{10}\right)_{4}\right] \cdot X \mathrm{H}_{2} \mathrm{O}$ & 10 & 120 & Trace \\
\hline 9 & $\begin{array}{l}\text { SBA-15/( }\left(\mathrm{CH}_{2}\right)_{3} \mathrm{~N}\left(\mathrm{CH}_{2} \mathrm{PO}_{3} \mathrm{H}_{2}\right) \\
\left(\mathrm{CH}_{2}\right)_{2}-\mathrm{N}\left(\mathrm{CH}_{2} \mathrm{PO}_{3} \mathrm{H}_{2}\right)_{2}(\text { ref. } 17 b)\end{array}$ & 10 & 90 & 62 \\
\hline 10 & 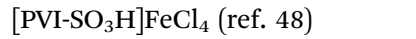 & 10 & 100 & 48 \\
\hline 11 & $p$-TSA & 10 & 120 & 48 \\
\hline 12 & $\mathrm{SSA}^{49}$ & $10 \mathrm{mg}$ & 110 & 50 \\
\hline 13 & $\mathrm{Et}_{3} \mathrm{~N}$ & 10 & 120 & - \\
\hline 14 & MHMHPA $^{18}$ & 10 & 90 & 50 \\
\hline 15 & Nano-SB-[PSIM] $\mathrm{Cl}^{50}$ & - & - & - \\
\hline 16 & {$\left[\mathrm{Py}_{-} \mathrm{SO}_{3} \mathrm{H}\right] \mathrm{Cl}^{51}$} & 10 & 120 & 35 \\
\hline 17 & $\mathrm{APVPB}^{52}$ & $10 \mathrm{mg}$ & 80 & 60 \\
\hline 18 & $\begin{array}{l}\mathrm{Fe}_{3} \mathrm{O}_{4} @ \mathrm{Co}(\mathrm{BDC})-\mathrm{NH}_{2} \\
\text { (ref. 53) }\end{array}$ & $10 \mathrm{mg}$ & 70 & 65 \\
\hline 19 & $\mathrm{H}_{3} \mathrm{PO}_{3}$ & 10 & 60 & 63 \\
\hline 20 & CQDs & $10 \mathrm{mg}$ & 45 & 70 \\
\hline 21 & CQDs- $\mathrm{N}\left(\mathrm{CH}_{2} \mathrm{PO}_{3} \mathrm{H}_{2}\right)_{2}$ (this work) & $10 \mathrm{mg}$ & 25 & 89 \\
\hline
\end{tabular}

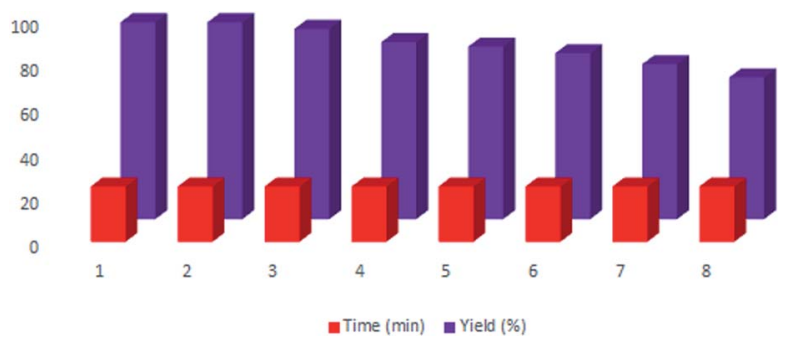

Fig. 9 Recyclability of CQDs- $\mathrm{N}\left(\mathrm{CH}_{2} \mathrm{PO}_{3} \mathrm{H}_{2}\right)_{2}$ for the synthesis of $4 \mathrm{H}$ pyran-3,5-dicarbonitrile derivatives.

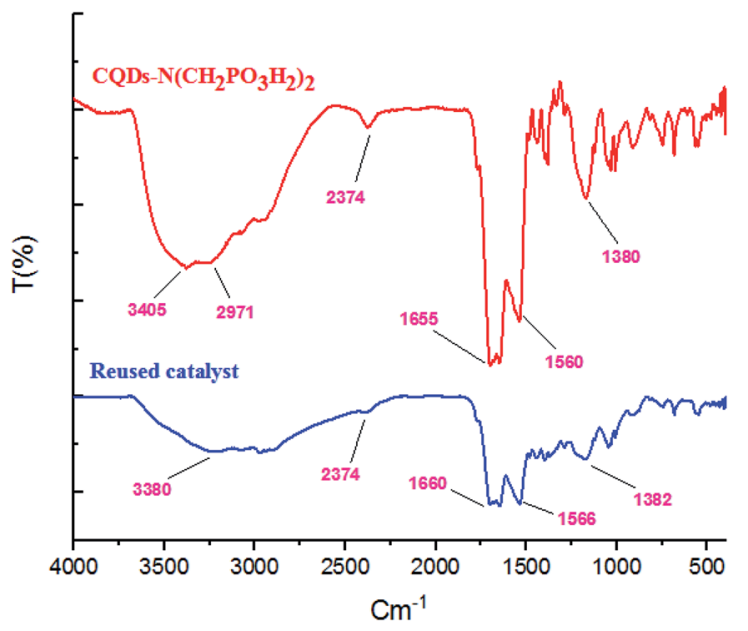

Fig. 10 The characterization of the reused catalysts after seven runs using FT-IR spectroscopy. 


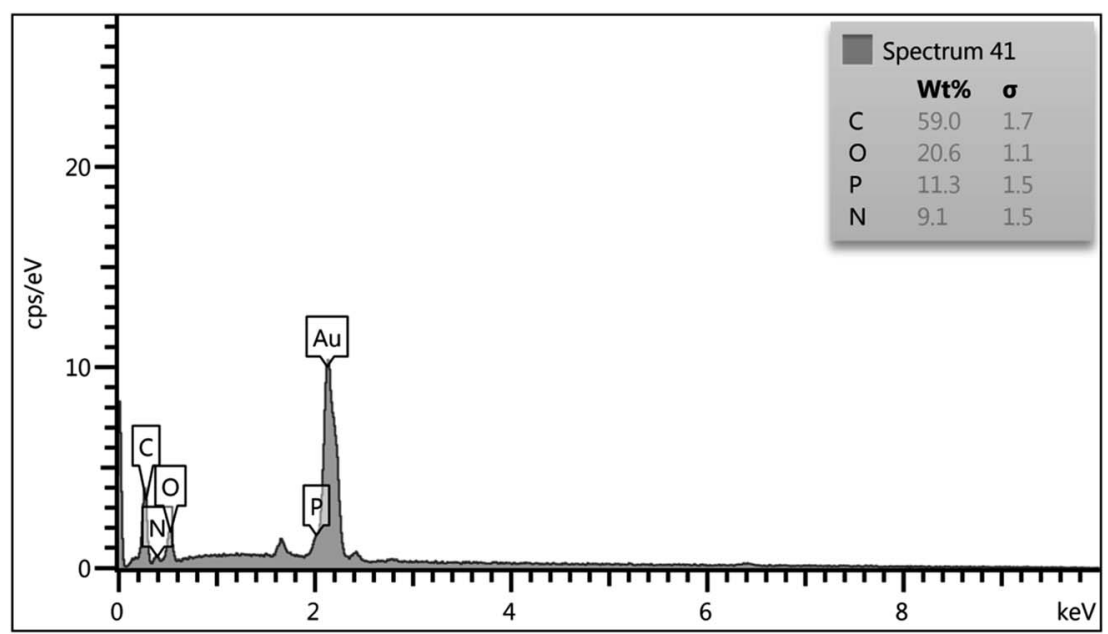

Fig. 11 The characterization of the reused catalysts after seven runs using energy dispersive X-ray analysis (EDX).

indol-3-yl)-4-phenyl-4H-pyran-3,5-dicarbonitrile derivatives; due to the shorter reaction times, higher yields and amount of applied catalyst. Also, the reusability of CQDs$\mathrm{N}\left(\mathrm{CH}_{2} \mathrm{PO}_{3} \mathrm{H}_{2}\right)_{2}$ as a catalyst for the preparation of 2-amino-6(2-methyl- $1 H$-indol-3-yl)-4-phenyl- $4 H$-pyran-3,5-

dicarbonitrile derivatives was examined in the above reaction. The results show that the catalyst has the potential to be recycled and reused up to 7 times without a significant decrease in its catalytic activity (Fig. 9). CQDs- $\left(\mathrm{CH}_{2} \mathrm{PO}_{3} \mathrm{H}_{2}\right)_{2}$ was also characterized by FT-IR and energy dispersive X-ray analysis (EDX) analysis after its application in the reaction. These spectra were same as those of the fresh catalyst (Fig. 10 and 11).

\section{Conclusion}

In conclusion, we have designed and introduced CQDs$\mathrm{N}\left(\mathrm{CH}_{2} \mathrm{PO}_{3} \mathrm{H}_{2}\right)_{2}$ as a novel heterogeneous nano-catalyst. It was identified using various techniques. CQDs- $\mathrm{N}\left(\mathrm{CH}_{2} \mathrm{PO}_{3} \mathrm{H}_{2}\right)_{2}$, as an efficient catalyst, was applied for the synthesis of multi substituted $4 H$-pyran-3,5-dicarbonitrile with indole moieties as candidates with biological interest. The presented methodology is not suitable for synthesis of pyridines with indole moieties. A short reaction time, clean and mild reaction conditions and the recycling of the catalyst are the major advantages of the presented work.

\section{Conflicts of interest}

There are no conflicts to declare.

\section{Acknowledgements}

We thank the Bu-Ali Sina University and Iran National Science Foundation (INSF) (grant number: 98020070) for financial support.

\section{References}

1 M. J. Molaei, Anal. Methods, 2020, 12, 1266.

2 M. J. Molaei, Sol. Energy, 2020, 196, 549.

3 X. Kou, S. Jiang, S. J. Park and L. Y. Meng, Dalton Trans., 2020, 49, 6915-6928.

4 J. M. Katzen, C. Tserkezis, Q. Cai, L. H. Li, J. M. Kim, G. Lee, G. Yi, W. R. Hendren, E. J. G. Santos, R. M. Bowman and F. Huang, ACS Appl. Mater. Interfaces, 2020, 12, 19866.

5 G. Kalaiyarasan, J. Joseph and P. Kumar, ACS Omega, 2020, 5, 22278.

6 F. Li, T. Li, C. Sun, J. Xia, Y. Jiao and H. Xu, Angew. Chem., Int. Ed., 2017, 56, 9910.

7 X. Xu, R. Ray, Y. Gu, H. J. Ploehn, L. Gearheart, K. Raker and W. A. Scrivens, J. Am. Chem. Soc., 2004, 126, 12736.

8 H. Li, X. He, Z. Kang, H. Huang, Y. Liu, J. Liu, S. Lian, C. H. A. Tsang, X. Yang and S. T. Lee, Angew. Chem., 2010, 122, 4532.

9 W. Su, R. Guo, F. Yuan, Y. Li, X. Li, Y. Zhang, S. Zhou and L. Fan, J. Phys. Chem. Lett., 2020, 11, 1357.

10 B. C. Martindale, G. A. Hutton, C. A. Caputo and E. Reisner, J. Am. Chem. Soc., 2015, 137, 6018.

11 B. B. Karakoçak, A. Laradji, T. Primeau, M. Y. Berezin, S. Li and N. Revi, ACS Appl. Mater. Interfaces, 2021, 13, 277.

12 K. M. Chan, W. Xu, H. Kwon, A. M. Kietrys and E. T. Kool, J. Am. Chem. Soc., 2017, 139, 13147.

13 X. Xiao, Z. Shao and L. Yu, Chin. Chem. Lett., 2021, 23, 4647. 14 X. Wang, Y. Feng, P. Dong and J. Huang, Front. Chem., 2019, 7, 671 .

15 (a) C. Fujun, Y. Ping, L. Xiguang, L. Chunping and Q. Rongjun, Renewable Energy, 2014, 71, 61; (b) M. F. Mady and M. A. Kelland, Energy Fuels, 2017, 31, 4603; (c) A. Kadous, M. Didi and D. Villemin, J. Radioanal. Nucl. Chem., 2010, 284, 431.

16 S. Moradi, M. A. Zolfigol, M. Zarei, D. A. Alonso and A. Khoshnood, ChemistrySelect, 2018, 3, 3042.

17 (a) M. Zarei, M. A. Zolfigol, A. R. Moosavi-Zare, E. Noroozizadeh and S. Rostamnia, ChemistrySelect, 2018, 
3, 12144; (b) F. Jalili, M. Zarei, M. A. Zolfigol, S. Rostamnia and A. R. Moosavi-Zare, Microporous Mesoporous Mater., 2020, 294, 109865.

18 J. Afsar, M. A. Zolfigol, A. Khazaei, M. Zarei, Y. Gu, D. A. Alonso and A. Khoshnood, Mol. Catal., 2020, 482, 110666.

19 S. Babaee, M. Zarei, H. Sepehrmansourie, M. A. Zolfigol and S. Rostamnia, ACS Omega, 2020, 5, 6240.

20 S. Babaee, M. Zarei, M. A. Zolfigol, S. Khazalpour, M. Hasani, U. Rinner, R. Schirhagl, N. Norouzi and S. Rostamnia, RSC Adv. , 2021, 11, 2141.

21 H. Sepehrmansouri, M. Zarei, M. A. Zolfigol, A. R. MoosaviZare, S. Rostamnia and S. Moradi, Mol. Catal., 2020, 481, 110303.

22 S. Kalhor, M. Zarei, H. Sepehrmansourie, M. A. Zolfigol, H. Shi, J. Wang, J. Arjomandi, M. Hasanie and R. Schirhagl, Mol. Catal., 2021, 507, 111549.

23 (a) A. Varvaresou, A. Tsantili-Kakoulidou, T. SiatraPapastaikoudi and E. Tiligada, Arzneimittelforschung, 2000, 50, 48; (b) J. Slaett, I. Romero and J. Bergman, Synth., 2004, 16, 2760; (c) F. Palluotto, A. Carotti, G. Casini, M. Ferappi, A. Rosato, C. Vitali and F. Campagna, Il Farmaco, 1999, 54, 191; (d) M. Shiri, Chem. Rev., 2012, 112, 3508; (e) M. Shiri, M. A. Zolfigol, H. G. Kruger and Z. Tanbakouchian, Chem. Rev., 2010, 110, 2250.

24 (a) P. Kutsky, T. M. Dzurilla and A. Sabova, Collect. Czech. Chem. Commun., 1999, 64, 348; (b) P. Kutschy, M. Dzurilla, M. Takasugi, M. Török, I. Achbergerová, R. Homzová and M. Rácová, Tetrahedron, 1998, 54, 3549.

25 S. A. Zotova, T. M. Korneeva, V. I. Shvedov, N. I. Fadeeva, I. A. Leneva, I. T. Fedyakina, M. L. Khristova, I. S. Nikolaeva, V. V. Peters and T. A. Gus'kova, Pharm. Chem. J., 1995, 29, 57.

26 N. V. Lakshmi, P. Thirumurugan, K. M. Noorulla and P. T. Perumal, Bioorg. Med. Chem. Lett., 2010, 20, 5054.

27 R. D. Dillard, N. J. Bach, S. E. Draheim, D. R. Berry, D. G. Carlson, N. Y. Chirgadze and J. P. Wery, J. Med. Chem., 1996, 39, 5119.

28 S. M. Gomha and H. A. Abdel-Aziz, Bull. Korean Chem. Soc., 2012, 33, 2985.

29 S. Battagba, E. Boldrini, F. D. Settimo, G. Dondio, C. L. Motta, A. M. Marini and G. Primofiore, Eur. J. Med. Chem., 1999, 34, 93.

30 L. Garuti, M. Roberti, T. Rossi, M. Castelli and M. Malagoli, Eur. J. Med. Chem., 1998, 33, 43.

31 (a) M. A. Radwan, E. A. Ragab, N. M. Sabry and S. M. ElShenawy, Bioorg. Med. Chem., 2007, 15, 3832; (b) S. L. Zhu, S. J. Ji, X. M. Su, C. Sun and Y. Liu, Tetrahedron Lett., 2008, 49, 1777; (c) A. A. Fadda, A. El-Mekabaty, I. A. Mousa and K. M. Elattar, Synth. Commun., 2014, 44, 1579; (d) P. Thirumurugan, A. Nandakumar, D. Muralidharan and P. T. Paramasivan, J. Comb. Chem., 2010, 12, 161.
32 D. Kumar, P. Sharma, H. Singh, K. Nepali, G. K. Gupta, S. K. Jain and F. Ntie-Kang, RSC Adv., 2017, 7, 36977.

33 Saigal, M. Irfan, P. Khan, M. Abid and M. M. Khan, ACS Omega, 2019, 4, 16794.

34 P. K. Singh and O. Silakari, ChemMedChem, 2018, 13, 1071. 35 S. Gupta, S. Adhikary, R. K. Modukuri, D. Choudhary, R. Trivedi and K. V. Sashidhara, Bioorg. Med. Chem. Lett., 2018, 28, 1719.

36 S. P. Khare, T. R. Deshmukh, S. V. Akolkar, J. N. Sangshetti, V. M. Khedkar and B. B. Shingate, Res. Chem. Intermed., 2019, 45, 5159.

37 Z. Tashrifi, M. Mohammadi-Khanaposhtani, H. Hamedifar, B. Larijani, S. Ansari and M. Mahdavi, Mol. Diversity, 2020, 1. 38 (a) P. N. Amaniampong and F. Jerome, Curr. Opin. Green Sustain. Chem., 2020, 22, 7; (b) J. Amaro-Gahete, R. Klee, D. Esquivel, J. R. Ruiz, C. Jiménez-Sanchidrián and F. J. Romero-Salguero, Ultrason. Sonochem., 2019, 50, 59.

39 F. Bigdeli, F. Rouhani, A. Morsali and A. Ramazani, Ultrason. Sonochem., 2020, 62, 104862.

40 J. Schneider, C. J. Reckmeier, Y. Xiong, M. von Seckendorff, A. S. Susha, P. Kasák and A. L. Rogach, J. Phys. Chem. C, 2017, 121, 2014.

41 M. Shiri, Chem. Rev., 2012, 112, 3508.

42 M. Shiri, M. A. Zolfigol, H. G. Kruger and Z. Tanbakouchian, Chem. Rev., 2010, 110, 2250.

43 H. Kooshki, A. Sobhani-Nasab, M. Eghbali-Arani, F. Ahmadi, V. Ameri and M. Rahimi-Nasrabadi, Sep. Purif. Technol, 2019, 211, 873.

44 T. Chen, X. P. Xu and S. J. Ji, J. Heterocycl. Chem., 2013, 50, 244.

45 N. V. Lakshmi, P. Thirumurugan, K. M. Noorulla and P. T. Perumal, Bioorg. Med. Chem. Lett., 2010, 20, 5054.

46 L. Kheirkhah, M. Mamaghani, A. Yahyazadeh and N. O. Mahmoodi, Appl. Organomet. Chem., 2018, 32, 4072.

47 M. Zarei, H. Sepehrmansourie, M. A. Zolfigol, R. Karamian and S. H. Moazzami Farida, New J. Chem., 2018, 42, 14308.

48 H. Sepehrmansourie, M. Zarei, R. Taghavi and M. A. Zolfigol, ACS Omega, 2019, 4, 17379.

49 (a) M. A. Zolfigol, Tetrahedron, 2001, 57, 9509; (b) H. Sepehrmansourie, Iran. J. Catal., 2020, 10, 175.

50 A. Zare, M. Merajoddin, A. R. Moosavi-Zare, M. Zarei, M. H. Beyzavi and M. A. Zolfigol, Res. Chem. Intermed., 2016, 42, 2365.

51 A. R. Moosavi-Zare, M. A. Zolfigol, M. Zarei, V. Khakyzadeh and A. Hasaninejad, Appl. Catal., A, 2013, 467, 61.

52 E. Noroozizadeh, A. R. Moosavi-Zare, M. A. Zolfigol, M. Zarei, R. Karamian, M. Asadbegy, S. Yari and S. H. M. Farida, J. Iran. Chem. Soc., 2018, 15, 471.

53 H. Sepehrmansourie, M. Zarei, M. A. Zolfigol, S. Babaee and S. Rostamnia, Sci. Rep., 2021, 11, 5279. 